Research Article

\title{
Effects of Oxygen on Renal Function and Oxidative Stress During Hypothermic Machine Perfusion in an Experimental Porcine Model of Kidney Donation after Cardiac Death
}

Victoria Gómez-Dos-Santos ${ }^{1,}{ }^{*}$, Vital Hevia Palacios ${ }^{1}$, María Laura García-Bermejo ${ }^{2}$, Alberto AlcázarGonzález ${ }^{3}$, Miren Edurne Ramos-Muñoz ${ }^{2}$, Laura Salinas-Muñoz ${ }^{2}$, Elisa Conde-Moreno ${ }^{2}$, Alejandro Escobar-Peso ${ }^{3}$, Ana Belén Serrano-Romero ${ }^{4}$, Ana Saiz-González ${ }^{5}$, Miriam Menacho-Román ${ }^{6}$, Francisco Javier Burgos-Revilla ${ }^{1}$

1. Urology Department. Ramón y Cajal Hospital. IRYCIS. Alcalá University, Madrid, Spain; E-Mails: vgomezd69@gmail.com; vital.hevia.uro@gmail.com; burgosrevillajavier@gmail.com

2. Biomarkers and Therapeutic Targets Group. Ramón y Cajal Hospital. IRYCIS, Madrid, Spain; EMails: garciabermejo@gmail.com; varada22@hotmail.com; laurasalinas04@gmail.com; elisa.condem@gmail.com

3. Research Department. Ramón y Cajal Hospital. IRYCIS, Madrid, Spain; E-Mails: alberto.alcazar@hrc.es; alejandro.escobar@hrc.es

4. Anesthesiology Department. Ramón y Cajal Hospital. IRYCIS. Alcalá University, Madrid, Spain; EMail: anab serrano@yahoo.es

5. Pathology Department. Ramón y Cajal Hospital. IRYCIS. Alcalá University, Madrid, Spain; E-Mail: ana.saiz@salud.madrid.org

6. Biochemistry Department. Ramón y Cajal Hospital. IRYCIS, Madrid, Spain; E-Mail: m.menachoroman@gmail.com

* Correspondence: Victoria Gómez Dos Santos; E-Mails: vgomezd69@gmail.com; vgomezd@salud.madrid.org

Academic Editor: Wasim A. Dar

Special Issue: Preservation of Donor Organs

OBM Transplantation

2021, volume 5, issue 2

doi:10.21926/obm.transplant.2102144
Received: December 22, 2020

Accepted: May 05, 2021

Published: June 10, 2021

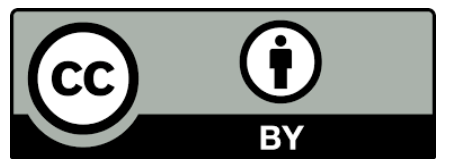

(C) 2021 by the author. This is an open access article distributed under the conditions of the Creative Commons by Attribution License, which permits unrestricted use, distribution, and reproduction in any medium or format, provided the original work is correctly cited. 


\begin{abstract}
The efficacy and safety of using high concentrations of oxygen during hypothermic machine perfusion (HMP) have not been fully elucidated to date. This study investigated the impact of administering high concentrations of oxygen on renal function during HMP in a porcine donation after circulatory death (DCD), as well as the metabolic and biochemical effects of this method. A randomized nonblinded cohort study was established in a porcine transplant (KT) model mimicking Maastricht type III DCD under oxygen-supplemented HMP (Ox-HMP) compared to non-supplemented (nOx-HMP) (LifePort ${ }^{\circledR}$ kidney transporter) conditions. The primary endpoint was evolution of renal function post-KT, whereas secondary endpoints included changes in perfusion dynamics, miRNA expression and cellular lesion measured by LDH and lactate levels in perfusate, lipid peroxidation in kidney biopsies, ATP generation, epithelial mesenchymal transition (EMT) and oxidative gene expression in cell cultures and histology evaluation. ATP generation and oxidative stress, as measured by lipid peroxidation, increased simultaneously after warm ischemia in the Ox-HMP group. Ox-HMP did not exhibit a significant effect on kidney function or animal survival. A significant increase in lipid peroxidation was observed in the Ox-HMP group. This resulted in a greater expression of the genes responsible for producing superoxide dismutase 1 (SOD-1) and catalase oxygenation enzymes, although only SOD-1 showed statistical significance. Respiratory chain dysfunction was maintained in the Ox-HMP group with a non-significant decrease in ATP production, increased proton leakage, and a decrease in respiratory reserve. Regarding epithelialmesenchymal transition, an upward trend in the expression of vimentin, fibronectin, and collagen genes was observed only in the Ox-HMP group. Finally, the expression levels of miR101 and miR-126, related to characteristic functions of the tubular epithelium, were significantly modified (miRNA levels expressed as DCT. A brief bubble Ox-HMP treatment did not show a clear positive effect on renal function and oxidative stress markers. The role and safety of adding oxygen during HMP still need to be elucidated. Currently, this Ox-HMP method cannot be considered standard practice.
\end{abstract}

\title{
Keywords
}

Oxygenated machine perfusion; ischemia-reperfusion injury; oxidative stress; miRNAs; donation after cardiac death; kidney transplantation

\section{Introduction}

The increasingly severe shortage of organs has led to the acceptance of donors with higher risks, such as expanded criteria donors (ECD) and donation after cardiac death (DCD) [1-3]. Kidneys from high-risk donors tend to be more sensitive to the stresses of preservation, leading to higher rates of delayed graft function (DGF) and primary nonfunction (PNF) [4]. Hypothermic machine perfusion (HMP) improves the functional results of kidney graft in clinics [5-8].

Static cold storage (SCS) and HMP are both based on metabolism suppression due to hypothermia. However, even at $4^{\circ} \mathrm{C}$, approximately $10 \%$ of the physiological metabolic rate remains active, suggesting that oxygen continues to be consumed $[9,10]$. The potential benefit of oxygen 
supplementation to support this low metabolic rate under low-temperature conditions is debated. Supplying additional oxygen may support mitochondrial ATP synthesis and delay injury, although the optimal level of oxygen has not been determined [11-15]. Despite the proposed benefits of oxygenation, damage due to reactive oxygen species (ROS) is a potential drawback of this method. Any potential metabolic benefits of organ oxygenation must therefore be weighed against the potentially deleterious effects of ROS [16-18]. Previous human and animal studies have used a variety of methods that have yielded inconsistent but promising results in terms of functional outcomes $[19,20]$. Active oxygenation can be done during HMP at different time points that include continuous delivery and partial delivery methods immediately after the start of HMP or at the final period of HMP. Limited data are available on the efficacy of the different active oxygenation methods, although end-ischemic active oxygenated HMP is probably the most convenient to apply in a clinical setting for organ sharing. Initial active oxygenation is aimed to replenish ATP early after the warm ischemic stress. Oxygen is commonly delivered through a hollow-fiber membrane oxygenator built into the sterile disposable tubing set of the HMP device. Life-Port technology permits the use of a bubble perfusate surface oxygenator integrated into the removable lid of the ice container [21, 22].

Recently, several miRNAs have been identified and characterized as key mediators of the proximal tubule response to ischemia-reperfusion injury (IRI) [23-25]. Moreover, several studies have noted the potential applications of these miRNAs as diagnostic, prognostic, and predisposition biomarkers of acute kidney injury (AKI) [23-27]. Presently, renal flow rate and vascular resistance are the only accepted indicators of kidney viability during $\operatorname{HMP}[28,29]$. Several biochemical parameters and ischemic injury markers have been quantified in the renal effluent. However, they are not fully established, and their role in predicting kidney function in vivo is still controversial [3032]. miRNAs may represent biomarkers of cellular metabolic status and kidney graft function.

Oxidative stress linked to ROS production leads to distinctive cellular changes, such as oxidative DNA modifications and lipid peroxidation [33]. Malondialdehyde (MDA) production provides a sensitive assay for measuring lipid peroxidation [17, 34], and antioxidant enzyme levels can also indicate the cellular capacity to buffer $\operatorname{ROS}[35,36,37]$.

This study aims to compare the metabolic consequences in the form of renal function, changes in perfusion dynamics, subsequent damage triggered by oxidative stress, lipid peroxidation in kidney biopsies and epithelial-mesenchymal transition (EMT), oxidative gene expression in cell cultures, mitochondrial respiratory changes, and histological alterations between nOx-HMP and Ox-HMP. Additionally, miRNA expression in the preservation solution was also determined.

\section{Materials and Methods}

\subsection{Animal Model and Recovery of Organs}

The protocol followed was according to the Spanish Royal Decree 53/2013 and was approved by the local Animal Ethics Committee. A simple randomization technique by computer-generated random numbers at the Biostatistical Department was used to assign animals to the treatment groups.

Twenty-four animals were initially included in the study. However, five animals from the Ox-HMP group in the early period were excluded because of erratic oxygen pressures measured with a hollow-fiber membrane oxygenator built into the sterile disposable tubing set in the LifePort ${ }^{\circledR}$ 
kidney transporter. Nineteen animals ( $\mathrm{nOx}-\mathrm{HMP}=12 ; \mathrm{Ox}-\mathrm{HMP}=7$ ) were included in the miRNAs and lipid peroxidation assays; however, only 15 were finally transplanted (nOx-HMP =11; Ox-HMP = 4), and their renal function and survival were analyzed (Figure S1). Female pigs (age: 3.5 - 6.5 months; weight: 40 - $50 \mathrm{~kg}$ ) were obtained from a commercial farm.

An orthotopic autotransplantation model mimicking Maastricht type III DCD was performed. The surgical and graft preservation procedures continued for over two consecutive days. On day -1, the left kidney was exposed through midline laparotomy and retrieved after 30 min of renal artery clamping (warm ischemia time; WIT). Subsequently, the organ was cold flushed at $4^{\circ} \mathrm{C}$ with Celsior ${ }^{\circledR}$ (Genzyme; Cambridge, MA, USA). A wedge biopsy of the renal cortex was taken for histology and lipid peroxidation assays. Primary cell cultures were obtained for subsequent Seahorse $\mathrm{XF}^{\circledR}$ analysis, antioxidant, and epithelial-mesenchymal transition (EMT) gene expression. Kidneys were subjected to Ox-HMP and nOx-HMP treatment for $22 \mathrm{~h}$. On day 0 , after the end of HMP, a second wedge biopsy was taken for histology, cell cultivation, and lipid peroxidation assays. Subsequently, a right nephrectomy and autotransplantation with the preserved left kidney were performed. Animals were sacrificed on day 10 by lethal injection or earlier if they had severe transplantation complications (sacrificed by humane methods), and kidney grafts were retrieved for histology and lipid peroxidation assay.

\subsection{Hypothermic Machine Perfusion}

HMP was initiated using a LifePort ${ }^{\circledR}$ Kidney Transporter 1.0 (Organ Recovery Systems ORS, Itasca; IL, USA) at $30 \mathrm{~mm} \mathrm{Hg}$ pressure and using 1 L KPS-1 (ORS). In the nOx-HMP group, the organ was perfused without active oxygenation using ambient air inside the kidney container enclosed by the inner and outer lids. The standard LifePort ${ }^{\circledR}$ perfusion circuit was initially modified to incorporate a pediatric membrane oxygenator (Dideco Kids D100 neonatal oxygenator, Sorin Group; CO, USA) that was later replaced by a surface bubble oxygenator. This supplied the perfusate directly with $\mathrm{O}_{2}$ for $30 \mathrm{~min}$ at the beginning of the perfusion (Figure S2). Initially, $\mathrm{O}_{2}$ supplementation was achieved by passing $\mathrm{O}_{2}(100 \%, 500 \mathrm{~mL} / \mathrm{min})$ via a submerged perforated tubing segment for $20 \mathrm{~min}$ in wash mode with the cassette lids closed. Then, $\mathrm{O}_{2}(100 \%, 100 \mathrm{~mL} / \mathrm{min})$ was passed for 10 min more by administering it on top of the perfusate with both cassette lids closed in infusion mode.

HMP parameters were recorded at 1,30, and $60 \mathrm{~min}$, and end of the perfusion. Serial preservation samples were collected at baseline, 1, 30, 60, and $120 \mathrm{~min}$, and end of the HMP for the determination of $\mathrm{pO}_{2}, \mathrm{LDH}$, and lactate levels, and analysis of miRNA expression.

\subsection{Primary Cell Cultures}

Fresh renal tissue (30 - $50 \mathrm{mg}$ ) was excised under sterile conditions and digested in serum-free F12/DMEM containing collagenase $(10 \mathrm{mg} / \mathrm{mL})$ at $37^{\circ} \mathrm{C}$ for $1 \mathrm{~h}$. Then, the cells were centrifuged at $330 \mathrm{~g}$ for $5 \mathrm{~min}$ and seeded onto P60 plates in a complete cell culture medium; F12/DMEM supplemented with 10\% FBS, 1\% PSG, and 1\% ITS (Sigma Aldrich; Germany). Cells were grown and maintained for up to ten days before being subjected to the Seahorse analysis. The remaining cells were kept at $-80^{\circ} \mathrm{C}$ for assessment of gene expression. 


\subsection{Biochemical Assays}

\subsubsection{Oxygen Level Measurement}

Oxygen levels were measured in the perfusate by the blood gas clinical analyzer GEM Premier 4000 (Werfen; Barcelona, Spain). The automated microprocessor-controlled analyzer can measure $\mathrm{pH}, \mathrm{pCO}_{2}, \mathrm{pO}_{2}, \mathrm{Na}^{+}, \mathrm{K}^{+}$, and $\mathrm{Ca}^{2+}$, among other parameters of interest. Samples were taken from the sample port located at the return line of the perfusion circuit.

Some differences were found in the perfusion set up of the LifePort ${ }^{\circledast}$ Kidney Transporter in oxygenated machine perfusion depending on whether a hollow-fiber membrane oxygenator or a surface bubble oxygenator was used. In the membrane oxygenator, the oxygenated perfusate enters the circuit at the return line of the perfusion circuit. Whereas, in the surface bubble oxygenator, oxygen reaches the perfusate inside the watertight organ cassette that acts as the perfusate reservoir; the kidney was maintained partially submerged, and $\mathrm{O}_{2}$ dissolvement was enhanced by the circulating perfusate.

\subsubsection{Renal Function Evaluation}

Serum urea and creatinine were measured in blood samples obtained via the jugular catheter from the first day after surgery to the last day of survival to evaluate renal function. Serum creatinine and urea were estimated by colorimetric assays (Architect Analyzer c16000, Abbott Diagnostics; Orlando, FL, USA).

\subsubsection{LDH and Lactate in Perfusion Solution}

LDH was estimated by a colorimetric assay (Architect Analyzer c16000, Abbott Diagnostics; Orlando, FL, USA). Lactate was measured by using a selective electrode in a Werfen GEM4000 Analyzer (L' Hospitalet de Llobregat, Barcelona, Spain).

\subsection{4 miRNA Quantification in Perfusion Solution}

The perfusion solution was centrifuged at $1,000 \mathrm{~g}$ for $5 \mathrm{~min}$ at $4^{\circ} \mathrm{C}$ and stored at $-80{ }^{\circ} \mathrm{C}$ before the miRNA quantification analysis. Total RNA was extracted from a $200-\mu \mathrm{L}$ sample using the miRNeasy mini kit (Qiagen; Hilden, Germany). A sample of the eluted RNA ( $4 \mu \mathrm{L})$ was used as a template for the generation of CDNA by reverse transcription using the Universal RT miRNA PCR System (Qiagen; Hilden, Germany). The CDNA was diluted with nuclease-free sterile water (1:11), and $4 \mu \mathrm{L}$ of the diluted sample was used as the template for the PCR analyses performed using SYBR Green and specific probes available commercially (Qiagen; Hilden, Germany) for each miRNA of interest. Quantitative real-time PCR (qRT-PCR) was performed using the Light Cycler 480 system (Roche; Basilea, Switzerland) according to the manufacturer's instructions. Exogenous UniSP2 added before RNA extraction was used as a technical housekeeping gene. All reactions were carried out in triplicate, and miRNA expression was expressed as

$$
\Delta \mathrm{Ct}=\text { tested miRNA Ct- technical housekeeping miRNA Ct }
$$




\subsubsection{Determining Markers of Oxidative Stress}

To determine the markers of oxidative stress, lipid peroxidation was evaluated by the detection of end products, such as MDA, resulting from the oxidation of polyunsaturated lipids. Lipid peroxidation was determined by the reaction of MDA with thiobarbituric acid (TBA) to form a colorimetric product proportional to the MDA present, and the product was measured at $540 \mathrm{~nm}$. MDA levels (in pmol) were determined according to a calibration curve with an MDA standard and normalized for protein content.

\subsubsection{Analysis of Mitochondrial Respiration}

A Seahorse $\mathrm{XF}^{\circledR}$ Cell Mito Stress assay (Agilent; Santa Clara, CA, USA) was performed to check mitochondrial function. For this, 10,000 cells per well were plated in Seahorse XF Cell Culture Microplates using a complete cell culture growth medium (F12/DMEM medium, 10\% FBS, 1\% PSG, and $1 \%$ ITS) for $48 \mathrm{~h}$. Twenty-four hours before measurement, the Seahorse respirometer cartridge, which houses the probes, was hydrated by adding $200 \mu \mathrm{L}$ XF calibrant to each well followed by overnight incubation at $37^{\circ} \mathrm{C}$. For measurement, the complete medium in the cell culture microplate was replaced by Seahorse cell medium (DMEM medium, $0.5 \mathrm{mM}$ pyruvate, $2.5 \mathrm{mM}$ glutamine, and $17.5 \mathrm{mM}$ glucose at $\mathrm{pH} 7.4$ ) and placed into a $37^{\circ} \mathrm{C}$ non- $\mathrm{CO}_{2}$ incubator for $45 \mathrm{~min}-1$ $\mathrm{h}$ before the assay was performed. Meanwhile, compound stock solutions were prepared according to the manufacturer's instructions ( $1 \mu \mathrm{M}$ oligomycin, $2 \mu \mathrm{M} \mathrm{FCCP}$, and $5 \mu \mathrm{M}$ rotenone/antimycin $\mathrm{A}$ ) and loaded into the injection ports on sensor cartridges. The oxygen consumption rate (OCR) of cells was monitored by the Seahorse XF Extracellular Flux Analyzer, and data were generated automatically by the Seahorse XF Mito Stress Test Report Generator using the Wave software.

\subsubsection{Antioxidant and EMT Gene Expression}

For the expression of antioxidant and EMT genes, cells were initially lysed into $1 \mathrm{ml}$ of Tri-Reagent (Ambion; Austin, TX, USA). Total RNA was then extracted and quantified using a Nanodrop 2000 (Thermo Scientific; Waltham, MA, USA). The cDNA was obtained from $2 \mu \mathrm{g}$ of total RNA from each sample using the Transcriptor First-Strand Synthesis kit (Roche; Basilea, Switzerland), and $1 \mu \mathrm{L}$ of cDNA sample was used as the template for PCR with LightCycler 480 SYBR Green I Master (Roche; Basilea, Switzerland) using specific primers (see Table 1) and following the manufacturer's instructions. PCR was performed using the Lightcycler 480 (Roche; Basilea, Switzerland). Each sample was done in triplicate, and the data were normalized for 285 mRNA levels. Primer sequences used for gene amplification are detailed in Table 1.

Table 1 Primer sequences used in qRT-PCR of antioxidant and EMT genes.

\begin{tabular}{lll}
\hline \multicolumn{1}{c}{ GENE } & \multicolumn{1}{c}{ PRIMER } & \multicolumn{1}{c}{ SECUENCE 5'-3' } \\
\hline $28 \mathrm{~S}$ & Forward & CAGTACGAATACAGACCG \\
& Reverse & GGCAACAACACATCATCAG \\
E-cadherin & Forward & ACAGACCCAGTAACCAATG \\
& Reverse & CTGAGCAGGGATGAAGAT \\
Collagen & Forward & GAAGAAGACATCCCACCAGTCA \\
\hline
\end{tabular}




\begin{tabular}{|c|c|c|}
\hline & Reverse & CAGATCACGTCATCGCACAA \\
\hline \multirow[t]{2}{*}{ Fibronectin } & Forward & GAAAGAAATCAACCTTGCTCCTG \\
\hline & Reverse & GTCTGCTTGTCAAAGTGTCCT \\
\hline \multirow[t]{2}{*}{ Snail } & Forward & АССTCATCCAAGGACCACA \\
\hline & Reverse & TTCCTAGACTGGGCGTCA \\
\hline \multirow[t]{2}{*}{ Vimentin } & Forward & CCTTGACATTGAGATTGCCA \\
\hline & Reverse & AGTGAATCCAGATTAGTTTCCC \\
\hline \multirow[t]{2}{*}{ Superoxide Dismutase 1} & Forward & AAGATTCTGTGATCGCCCTC \\
\hline & Reverse & CAAACGACTTCCAGCATTTCC \\
\hline \multirow[t]{2}{*}{ Superoxide Dismutase 2} & Forward & ATTGCCGCTTGTTCTAACCA \\
\hline & Reverse & CAAATAGCTTTCAGGTAATCAGGT \\
\hline \multirow[t]{2}{*}{ Catalase } & Forward & GTTTCCTTCCTGTTCAGCGA \\
\hline & Reverse & GССТСТСССТTCTCATTAАСC \\
\hline
\end{tabular}

\subsection{Histopathological Study}

Biopsies were performed at two-time points; immediately after kidney harvesting and cold flushing (pre-perfusion) and immediately after finishing HMP preservation (post-perfusion). At the time of sacrifice, kidney grafts were obtained for histopathological studies. Specimens were fixed in $4 \%$ buffered formalin, dehydrated, embedded in paraffin, and stained with hematoxylin and eosin (H\&E, Sigma) for evaluation by light microscopy. Renal injury was scored by an experienced pathologist who was blinded to the groups. Three morphological parameters indicating renal parenchymal injury (inflammation, ischemic necrosis, and acute tubular necrosis) were assessed. A four-point scale was applied for each parameter based on the percentage of the visual field affected by lesions, where $0=$ no damage; 1 = lesser than $25 \%$ damage; $2=25 \%-50 \%$ damage; $3=$ greater than $50 \%$ damage.

\subsection{Statistical Analysis}

Statistical analysis was performed using SPSS Statistics v15.0 (IBM; Armonk, NY, USA). Data were expressed as means with standard error (SE) or medians with ranges and were assessed by unpaired Student's t-tests for normally distributed data and equality of variance, or by Mann-Whitney U-tests when these parameters were not met to determine significant differences between groups. Statistical significance was considered at $\mathrm{P}<0.05$.

\section{Results}

\subsection{Oxygen Level Estimation in Perfusion Solution}

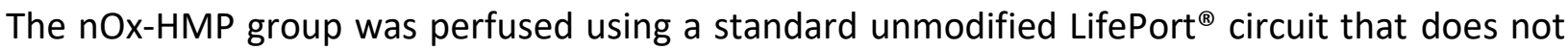
provide active perfusate oxygenation. The mean $\mathrm{pO}_{2}$ in the nOx-HMP group ranged from 162.9 $( \pm 33.5) \mathrm{mm} \mathrm{Hg}$ at the basal point to $92.9( \pm 18.5) \mathrm{mm} \mathrm{Hg}$ at the end of the perfusion (Figure S3a). The membrane oxygenator supplied $\mathrm{O}_{2}$ inconsistently (Figure $\mathrm{S} 3 \mathrm{~b}$ ), which was then substituted by a surface bubble oxygenator integrated into the LifePort ${ }^{\circledR}$ perfusion circuit. Data obtained from OxHMP using the hollow-fiber membrane oxygenator were excluded (Figure S1). Only data obtained 
from the Ox-HMP using the bubble surface oxygenator were analyzed $(n=4)$. In the Ox-HMP group, the mean $\mathrm{pO}_{2}$ changed from $164.4( \pm 13.9) \mathrm{mm} \mathrm{Hg}$ to $80.7( \pm 11.3) \mathrm{mm} \mathrm{Hg}$, similar to the $\mathrm{pO}_{2}$ values observed in the nOx-HMP group (Figure S3c). The highest $\mathrm{pO}_{2}$ was reached 30 min after $\mathrm{O}_{2}$ was uploaded (476.3 $\pm 102.6 \mathrm{~mm} \mathrm{Hg}$ ), which was only maintained for $15 \mathrm{~min}$ after the preload ended $\left(479.2 \pm 86.4 \mathrm{~mm} \mathrm{Hg}\right.$ ). The bubble surface oxygenator preloaded with $\mathrm{O}_{2}$ was not able to maintain supra-physiological $\mathrm{pO}_{2}$ until the end of the perfusion. However, the $\mathrm{pO}_{2}$ decline in the nOx-HMP group was slower than that in the Ox-HMP group. Brief initial $\mathrm{O}_{2}$ uploading during HMP still resulted in a two-fold $\mathrm{pO}_{2}$ level increase at the 120 min time point.

\subsection{Measurement of Perfusion Parameters}

The Ox-HMP and nOx-HMP groups showed similar flow patterns, starting with a steep increase within the first $30 \mathrm{~min}$ followed by a slow increase until the end of the preservation (Figure S4a). No significant differences in the flow rate during HMP were found. Resistive index (RI) patterns mirrored those of flow, and the mean RI was, therefore, lower for all time points in Ox-HMP kidneys but did not exhibit significant differences at any time point (Figure S4b).

\subsection{Evaluation of Renal Function}

Contralateral nephrectomy during the transplant enabled the use of post-KT animal serum creatinine levels to estimate preserved kidney function. A trend toward lower serum creatinine at day 3 post-KT was shown in the Ox-HMP group compared to its nOx-HMP counterpart; $12.3 \mathrm{mg} / \mathrm{dL}$ (9.9 - 16.9) and $11.0 \mathrm{mg} / \mathrm{dL}$ (6.2 - 14.0), respectively. However, no significant difference was found $(p=0.352)$. Changes in the concentration of creatinine during the post-transplant period are shown in Figure 1. The creatinine AUCs were 79.9 (95\% Cl: 57.1 - 102.7) and 56.2 (95\% Cl: 36.6 - 77.2), respectively.

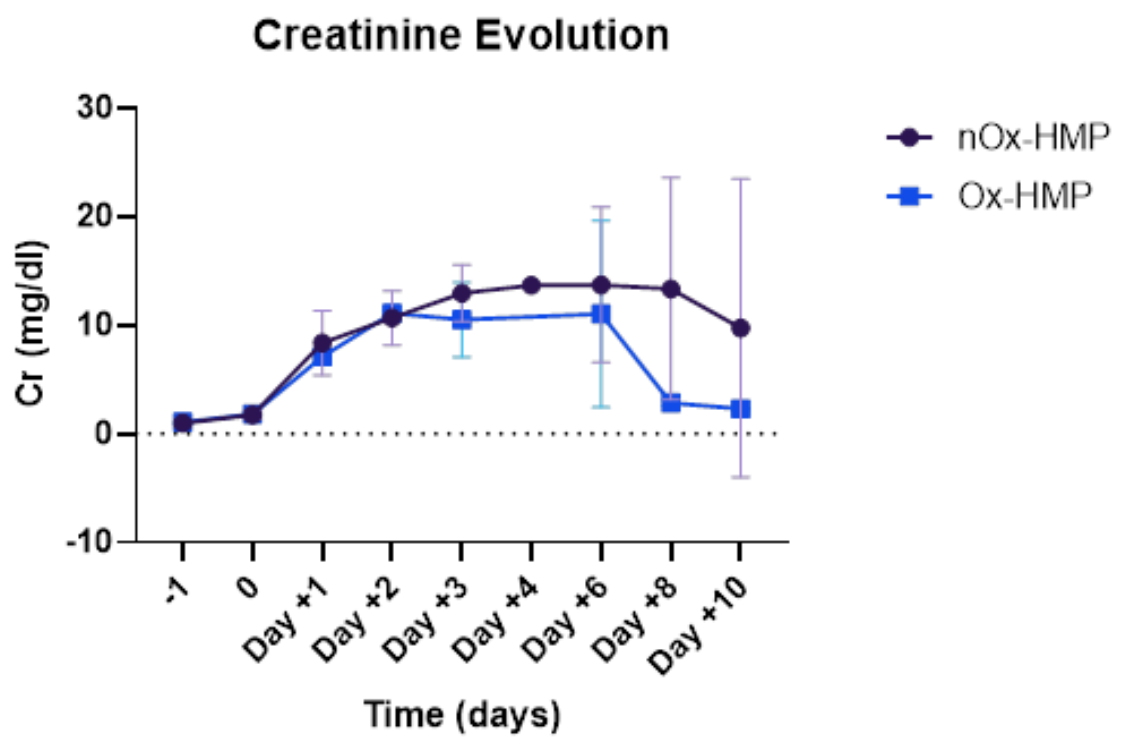

Figure 1 Changes in creatinine concentration during the post-transplant period. Plots show mean $( \pm S E)$. 


\subsection{Renal Tissue Injury: LDH and Lactate}

Oxygenation during HMP had no significant effect on the cellular LDH enzyme released in the perfusion solution. In contrast, concentrations of lactate in the perfusion solution samples were significantly higher in the Ox-HMP group (Figure 2), which was consistent with higher oxidative stress and lipid peroxidation (Figure 3 and Figure 4, respectively).
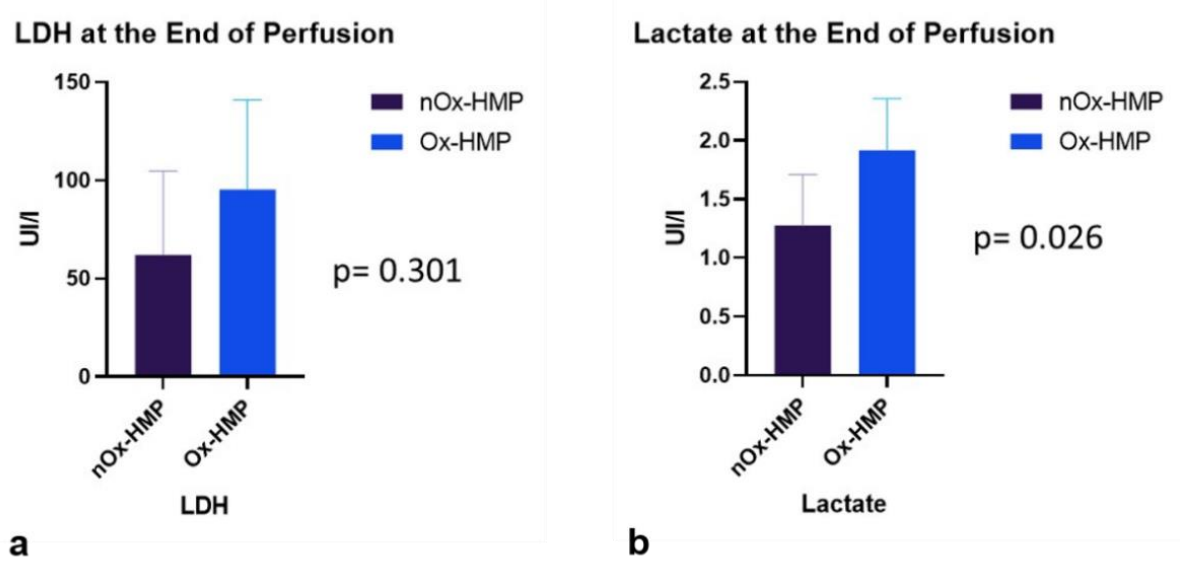

Figure 2 Concentrations of (a) LDH and (b) lactate in the perfusate at the end of the perfusion. Bar plots show mean (+SE).

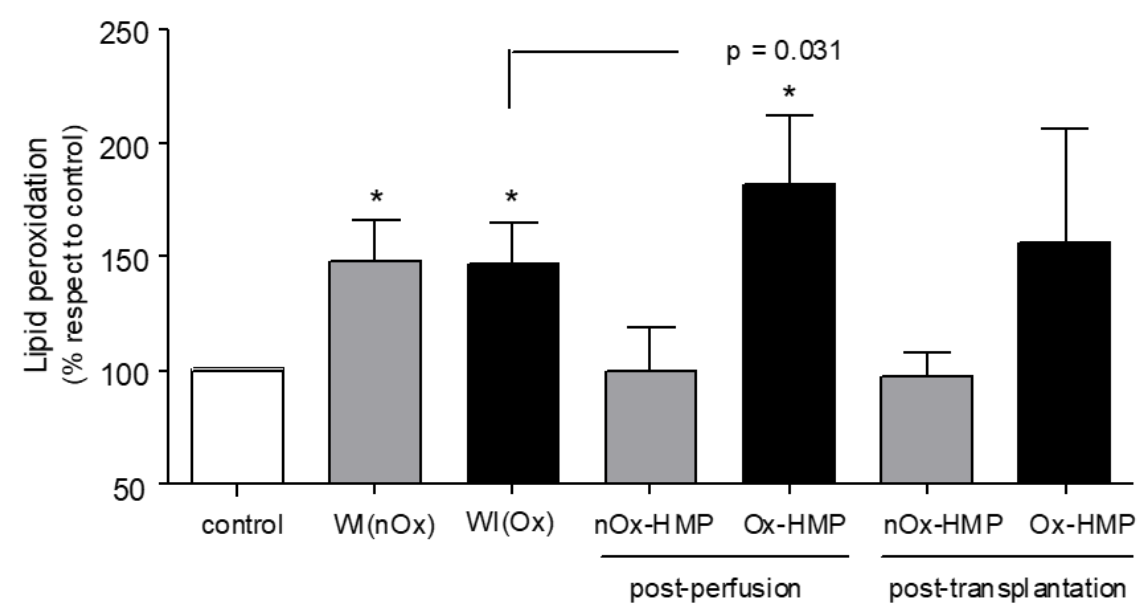

Figure 3 Effect of oxygen supplementation during renal preservation on lipid peroxidation. Control: wedge biopsy from healthy contralateral (right) kidney at the time of nephrectomy; WI: wedge biopsy from the left kidney graft after warm ischemia and before machine preservation with or without oxygenation (nOx vs. Ox); postperfusion: wedge biopsy from the left kidney graft after machine perfusion (nOx-HMP vs. Ox-HMP); post-transplantation: wedge biopsies after transplantation were obtained from the transplanted kidney when the animal was sacrificed (nOx-HMP vs. Ox-HMP). The percentage of lipid peroxidation and MDA present in control samples was considered as $100 \%$ (white bar, $24.1 \pm 0.2 \mathrm{pmol} / \mathrm{mg}$ ). Shown are statistically significant differences, compared to the control, analyzed by one-sample t-test $\left({ }^{*} p<0.05\right)$ and paired t-test $(p=0.031$ ) for the nOx or Ox groups. Bar plots show mean $(+S E)$. 

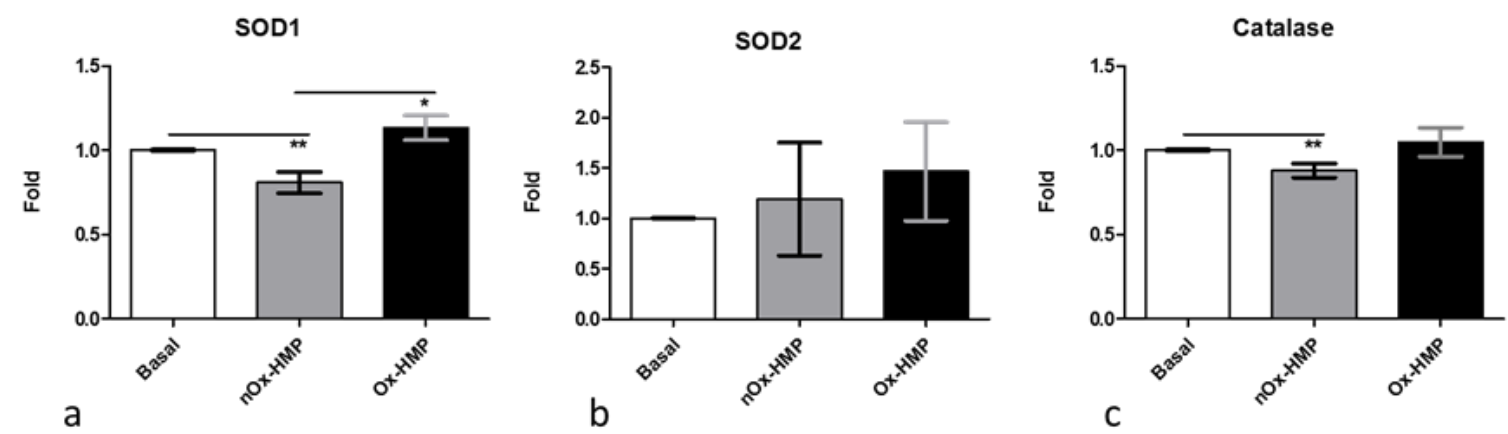

Figure 4 Antioxidant expression by qRT-PCR of the enzymes (a) SOD1, (b) SOD2, and (c) catalase. Bar plots show mean ( \pm SE). Significance levels denoted as $* p<0.05$ and $* * p<$ 0.001 .

\section{5 miRNA Levels in Perfusion Solution}

A combination of miRNAs with high diagnostic value in ischemic AKI damage, previously described by our group [24, 25], was tested and included the following miRNAs: miR-210, miR-126, miR-127, miR146, miR-10a, miR-101 miR-93, miR-27a, miR-26b, and miR-29a. Most of the miRNA expression in the perfusate was higher in Ox-HMP (lower DCTs) during perfusion, but only miRNA126 and miRNA-101 reached significant levels of expression at the end of the perfusion (Figure 5).

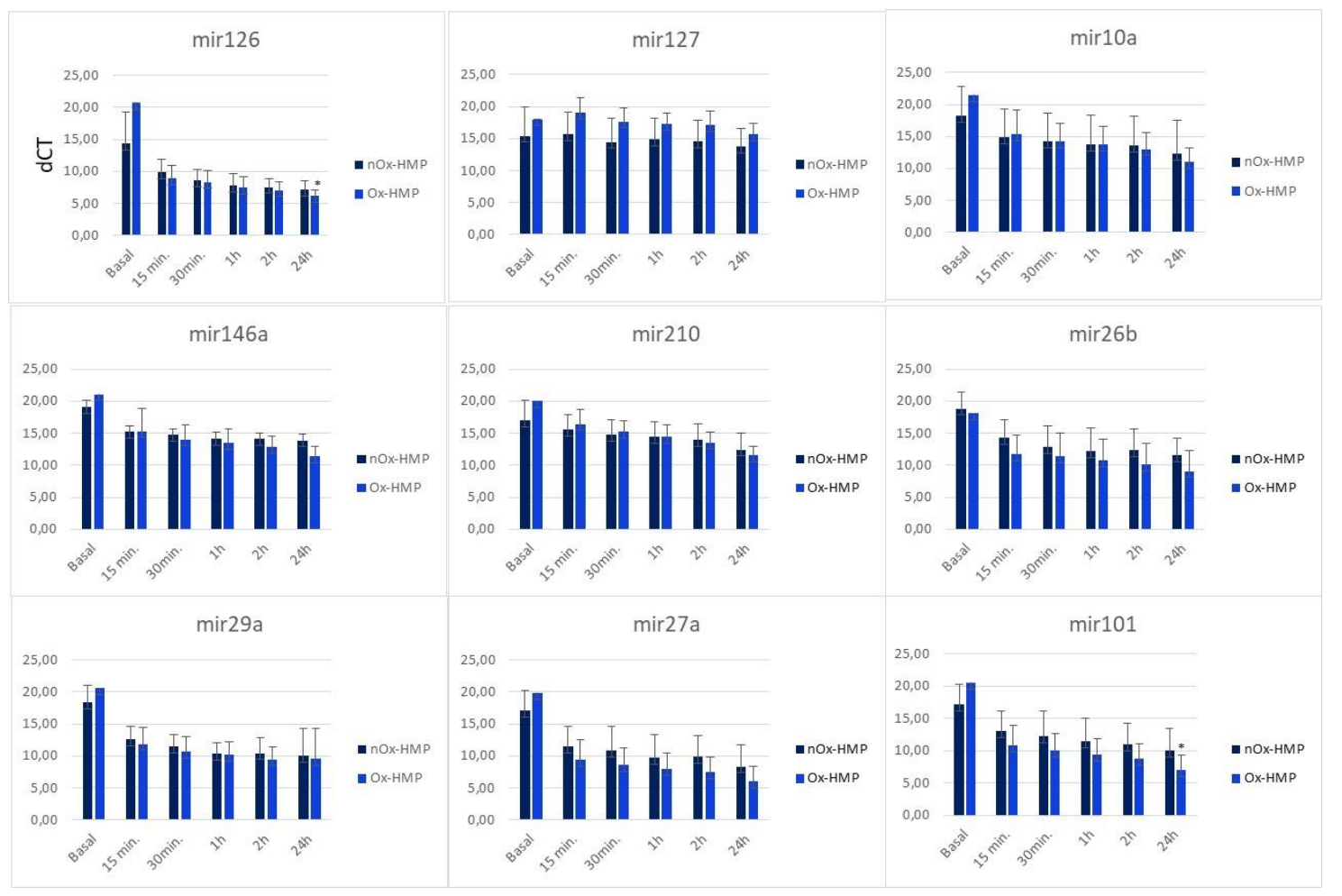

Figure 5 miRNA levels in preservation solution during perfusion, expressed as DCT. Bar plots show mean ( + SE). Significance level denoted by * $p \leq 0.05$. 


\subsection{Oxidative Stress Evaluation by Lipid Peroxidation Levels}

To determine the oxidative stress, tissue samples were separated into four groups by wedge biopsies. Biopsies obtained from the healthy contralateral (right) kidney at the time of nephrectomy preceding left autotransplantation at day 2 were considered as controls. Biopsies obtained from the left kidney graft immediately after the warm ischemia (WI) were considered as basal samples for lipid peroxidation (as MDA content), mitochondrial respiration, and gene expression assays. Biopsies from the left kidney graft were obtained after HMP (nOx-HMP or Ox-HMP) and before transplantation. Finally, biopsies from the nOx-HMP and Ox-HMP groups were obtained from the transplanted kidneys when the animals were sacrificed. Figure 3 shows MDA content at different time points previously defined. After the 30-min warm ischemia period that defined the controlled DCD model, significantly increased levels of lipid peroxidation were observed (WI groups). The nOxHMP reduced lipid peroxidation levels that matched the control MDA content. On the contrary, the MDA content significantly increased in the Ox-HMP group after perfusion, which was significantly higher than the lipid peroxidation observed after warm ischemia.

\subsection{Mitochondrial Respiration}

The results of mitochondrial respiration in primary cell cultures that were obtained after processing wedge kidney biopsies and analyzed by Seahorse $\mathrm{XF}^{\circledR}$ technology are summarized in Figure 6. The basal group corresponds to samples taken after the 30-min WIT and combines data from all animals posteriorly randomized to the nOx-HMP or Ox-HMP groups. Post-perfusion Seahorse $\mathrm{XF}^{\circledR}$ assays were performed in wedge biopsies taken from the left graft immediately after finishing machine preservation and before transplantation. They were placed either in the nOx-HMP or the Ox-HMP group (Figure 6).
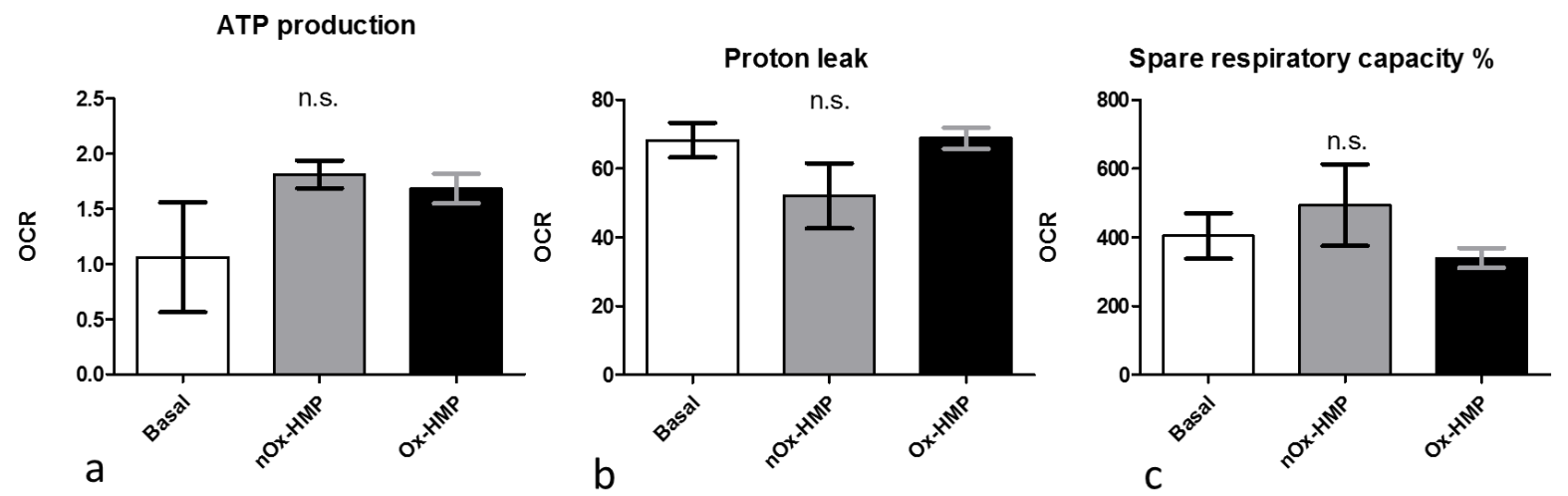

Figure 6 Shown is the effect of oxygen on mitochondrial function by measuring (a) ATP production, (b) proton leak, and (c) spare respiratory capacity (\%). Differences between nOx-HMP and Ox-HMP groups were not statistically significant. White bars: wedge biopsies taken after 30 min of warm ischemia time, gray bars: wedge biopsies taken after machine preservation from nOx-HMP grafts, and black bars: wedge biopsies taken after machine preservation from Ox-HMP grafts. Bar plots show mean (+ SE).

After 30 min of warm ischemia time, an increase in ATP production was observed (Figure 6a), which was slightly higher in the nOx-HMP group. A high level of proton leak (Figure $6 \mathrm{~b}$ ) and the 
corresponding low level of spare respiratory capacity (Figure 6c) represented the loss of respiratory chain efficiency after warm ischemia that was attenuated in nOx-HMP and worsened by the addition of oxygen in Ox-HMP. Differences between nOx-HMP and Ox-HMP groups were not statistically significant.

\subsection{Antioxidant Enzymes and EMT Gene Expression in Kidney Biopsies}

Figure 4 shows the expression of the genes for antioxidant enzymes that contribute to the general oxidative status in cells due to mitochondrial functions. Possibly due to lower oxidative stress (nOx-HMP), the level of SOD1 and catalase enzymes decreased significantly $(p<0.01)$ compared to their basal levels after the WIT period. In contrast, during Ox-HMP, oxidative stress and demands for SOD1 and catalase enzymes increased their levels compared to their respective basal levels. The mitochondrial SOD2 enzyme required more stringent controls, and its levels were more tightly regulated, thus reducing variability.

Expression of EMT markers was estimated by qRT-PCR. E-cadherin levels, indicating epithelial integrity and the absence of EMT, increased during nOx-HMP and after the WIT period (Figure S5) In contrast, vimentin, fibronectin, and collagen levels, indicating EMT, decreased during nOx-HMP (Figure S5). Ox-HMP induced the loss of the previously observed beneficial effects of HMP, leading to a decrease in E-cadherin expression and an increase in fibronectin, vimentin, and collagen levels compared to the levels observed after WIT (Figure S5). Differences between nOx-HMP and Ox-HMP groups analyzed by one-sample t-test, were not statistically significant.

\subsection{Lipid Peroxidation Correlates with Creatinine and Serum LDH Levels}

A significant correlation was found between post-perfusion lipid peroxidation levels in HMP biopsies and the post-KT functional situation, represented by creatinine levels on day 1 post-KT, and $\mathrm{LDH}$ at the end of the follow-up period (Figure 7). We found that lipid peroxidation was positively correlated with creatinine $(r=0.891 ; p=0.0030)$ and LDH $(r=0.769 ; p=0.0259) P)$. For correlation between lipid peroxidation post-perfusion and creatinine or LDH, data from both nOx-HMP and OxHMP were considered since the interest was to determine if lipid peroxidation correlated with another variable independent of the group studied.

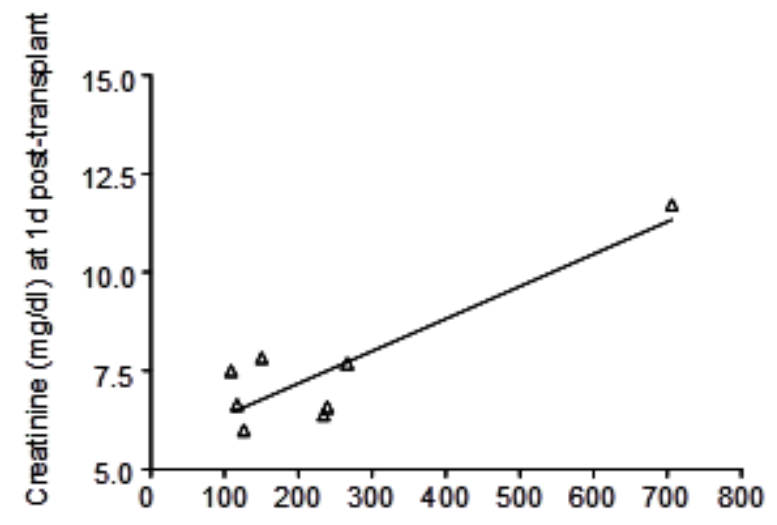

a

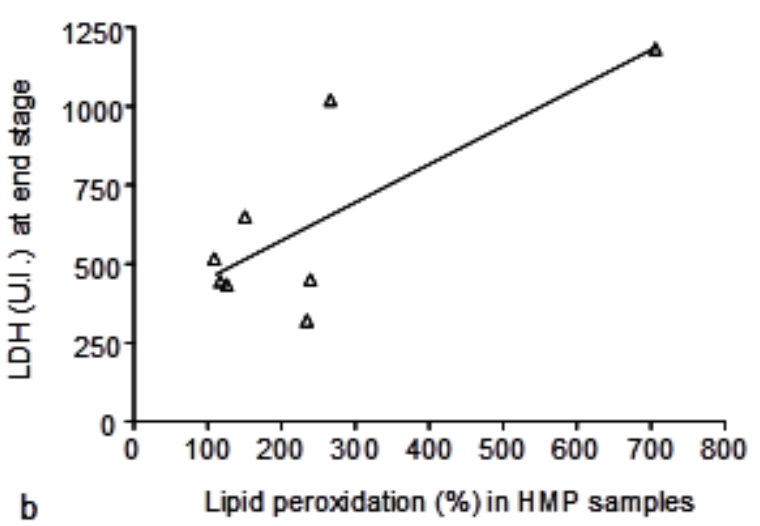

b

Figure 7 Correlations of lipid peroxidation with (a) creatinine and (b) LDH. Scatter plots with the line of best fit show positive correlations. 


\subsection{Histopathological Study: Acute Tubular Necrosis}

Paraffin-embedded biopsies from renal tissues taken pre and post-perfusion appeared to be normal upon visual inspection. No notable structural differences in the preimplantation were observed by light microscopy between both machine perfusion groups.

Cases exhibiting ischemic necrosis (IN) as an expression of maximal damage were observed in $27.3 \%(3 / 11)$ of the nOx-HMP group, and $18.2 \%(2 / 11)$ and $9.1 \%(1 / 11)$ showed severe and moderate acute tubular necrosis (ATN), respectively. Additionally, two animals exhibited severe $(18.2 \% ; 2 / 11)$ inflammatory infiltrates. Finally, $18.2 \%$ (2/11) of the animals showed normal histology. In contrast, 50\% (2/4) of the animals in the Ox-HMP group showed normal histology, 25\% (1/4) exhibited mild inflammatory infiltrates, and only the remaining $25 \%(1 / 4)$ showed $25-50 \%$ IN (Table 2).

Table 2 Histological results of grafts from biopsies after animal sacrifice. Light gray: nOxHMP group; Dark blue: Ox-HMP group; ATN: acute tubular necrosis; III: interstitial inflammatory infiltrate; IN: ischemic necrosis; G1: mild; G2: moderate; G3: severe.

\begin{tabular}{|c|c|c|c|c|c|c|c|c|c|c|c|c|c|c|c|}
\hline & \multicolumn{11}{|c|}{ nOx-HMP } & \multicolumn{4}{|c|}{ Ox-HMP } \\
\hline & 2 & 3 & 4 & 7 & 8 & 11 & 12 & 13 & 15 & 16 & 19 & 21 & 22 & 23 & 24 \\
\hline Normal & & & & & & & $x$ & & & $x$ & & & & $x$ & $x$ \\
\hline \multicolumn{16}{|l|}{ ATN G1 } \\
\hline ATN G2 & & & & & & & & $x$ & & & & & & & \\
\hline ATN G3 & & $x$ & $x$ & & & & & & & & & & & & \\
\hline IIIG1 & $x$ & $x$ & $x$ & & & & & & $x$ & & & $x$ & & & \\
\hline \multicolumn{16}{|l|}{ IIIG2 } \\
\hline IIIG3 & & & & & $x$ & & & & & & $x$ & & & & \\
\hline \multicolumn{16}{|l|}{ IN $<25 \%$} \\
\hline IN 25\%-50\% & & & & & & & & & & & & & $x$ & & \\
\hline IN $>50 \%$ & $x$ & & & $X$ & & $x$ & & & & & & & & & \\
\hline
\end{tabular}

\section{Discussion}

Experimental research on the addition of oxygen during HMP is scarce. This study reported the use of a porcine autotransplant kidney model comparing nOx-HMP with Ox-HMP (100\%). So far, only three studies have assessed SCS versus $100 \%$ oxygenated HMP in pre-clinical porcine autotransplantation models $[22,38,39]$. These studies had shown significant beneficial effects of Ox-HMP compared to SCS on renal function. HMP has proven to be beneficial for improving early graft function, particularly in kidneys from DCD donors $[5,7,8]$. Continuous recirculation of a cold perfusate through the kidneys at low pressure is thought to reduce vasospasm and protect the vascular endothelium by the modulation of Kruppel-like factor 2 and upregulation of endothelial nitric oxide synthase signaling pathways $[19,40]$. HMP also flushes out metabolites and supports a higher level of metabolism compared to static SCS. Recently, Venema et al. [41], in an ex vivo normothermic reperfusion model, specifically included nOx-HMP in the comparison and demonstrated its beneficial effects. Our study agreed with those findings and only compared actively oxygenated versus nOx-HMP [41]. 
To assess renal function, oxidative stress, cellular damage, and cellular energy were studied in an autotransplantation model mimicking Maastricht type III DCD. We found that active oxygenation during HMP was not significantly advantageous to renal function.

An overview of the literature of pre-clinical porcine kidney studies investigating different oxygen concentrations during continuous HMP and their effect on early graft function and ex vivo renal flow, using ex vivo normothermic reperfusion or an autotransplant model, is summarized in Table 3 and shows conflicting results $[15,22,38,39,41]$. Interestingly, in autotransplant models, the functional benefits of oxygen appeared to correlate with the ischemic insult, with comparable functional benefits reported following 30 or 60 min of preceding warm ischemia before preservation. In the absence of preceding warm ischemia, no benefit of active oxygenation was observed [15, 22, $38,39,41]$. We were unable to demonstrate a distinct functional benefit of oxygenation, although a non-significant decrease in peak serum creatinine at day 3 post-KT, and a faster decrease of creatinine to normal levels in the Ox-HMP group was observed (Figure1). 
Table 3 Summary of pre-clinical pig studies investigating different oxygen concentrations during continuous HMP of kidneys using an ex vivo normothermic reperfusion or an autotransplant model.

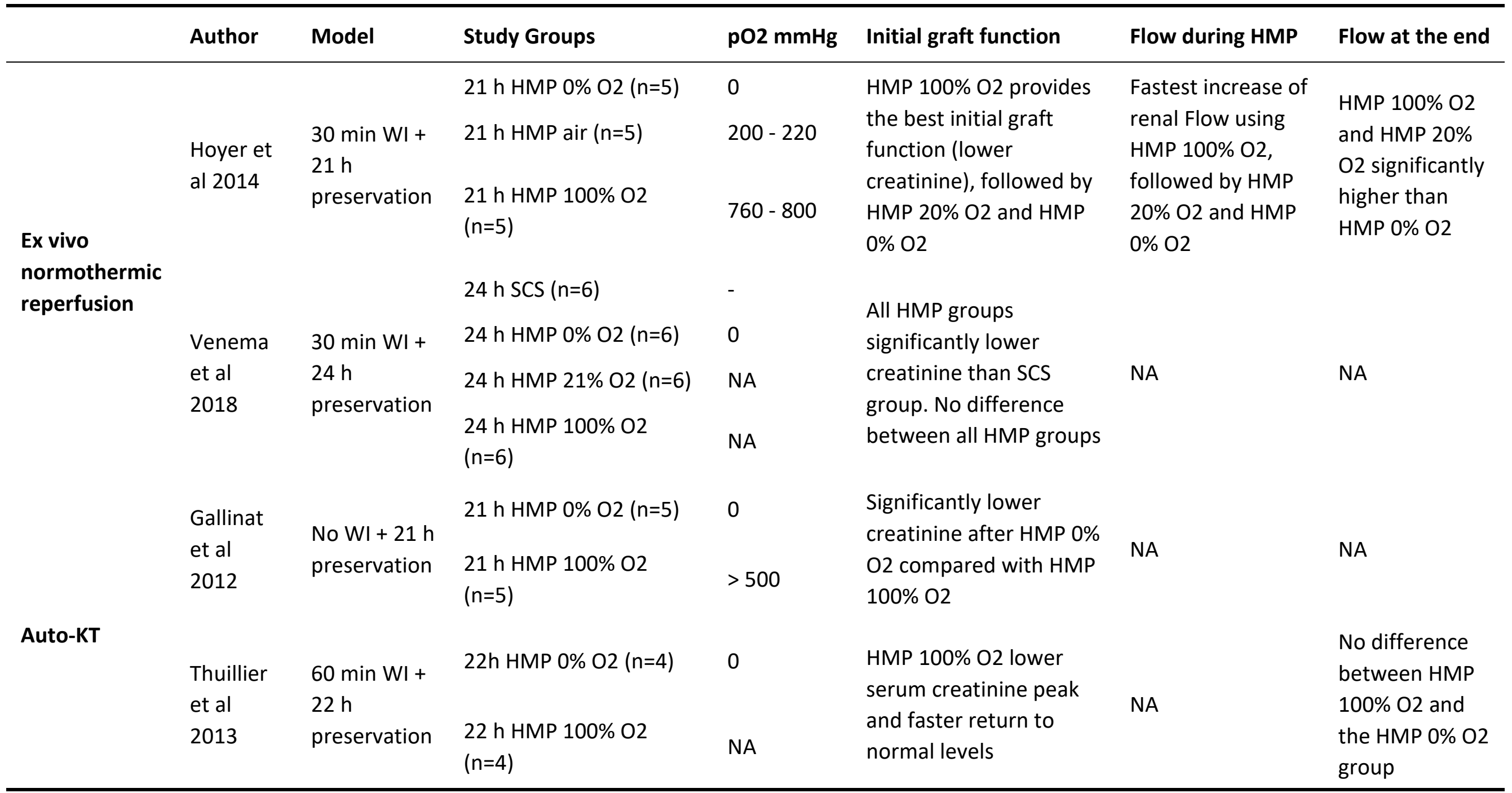




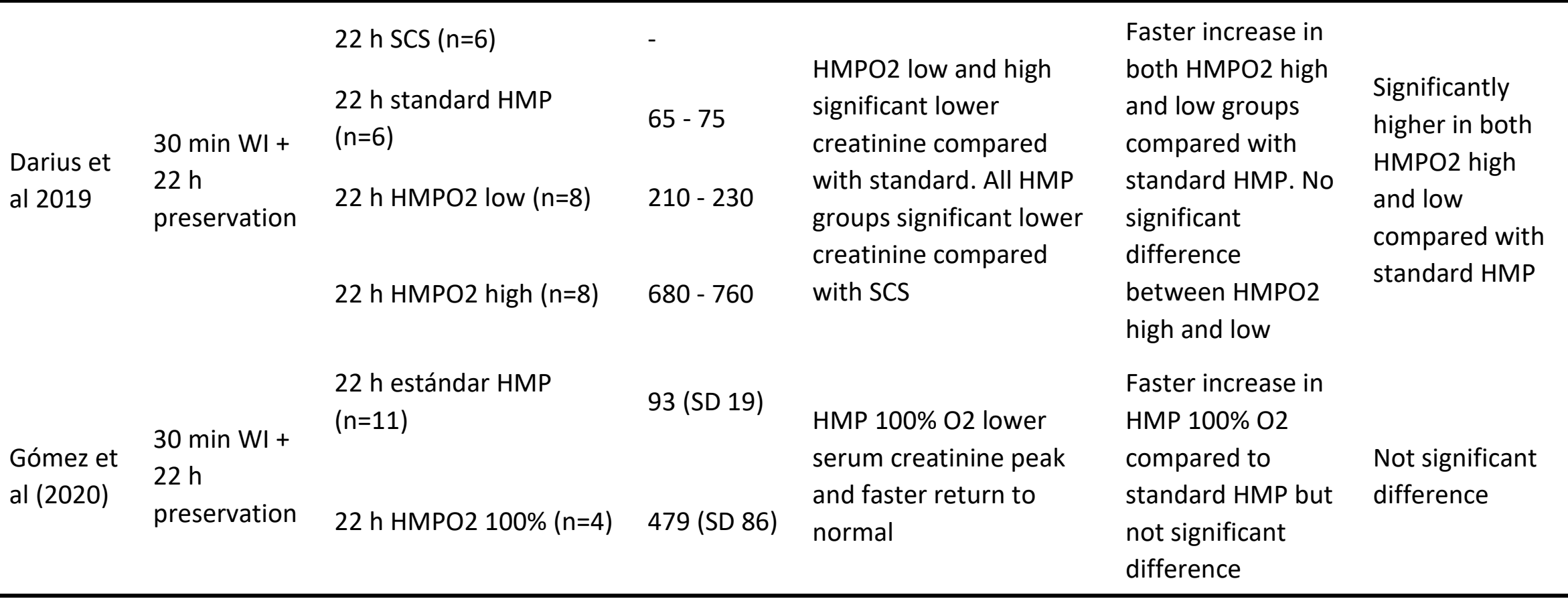


Histological evaluation of the preimplantation biopsies did not show any structural difference by light microscopy between both machine perfusion groups. This could reflect a limitation of our autotransplant model using young and healthy pigs without preexisting kidney diseases and only 30 min of preceding warm ischemia time before procurement. However, 30 min of warm ischemia is similar to the mean first warm ischemia time in most clinical DCD programs of kidney transplant and is frequently used in pre-clinical models [15, 37, 41, 42]. Notably, more frequent cases of IN and severe ATN and inflammatory infiltrate were observed in the nOx-HMP group that, although did not worsen renal function significantly, had a higher creatinine AUC (74.0-95\% Cl, $47.5-100.5)$ than that in the Ox-HMP group (36.2-95\% $\mathrm{Cl}, 25.6$ - 46.8).

We found, as expected, that the $\mathrm{pO}_{2}$ within the acellular perfusion fluid (with no designated oxygen carrier) could be increased during active oxygenation and depended on the percentage of oxygen delivered during $\mathrm{HMP}$. The mean $\mathrm{pO}_{2}$ in the Ox-HMP group declined with perfusion from $164.4( \pm 13.9) \mathrm{mm} \mathrm{Hg}$ to $80.7( \pm 11.3) \mathrm{mm} \mathrm{Hg}$, similar to the $\mathrm{pO}_{2}$ values observed in the nOx-HMP group. The highest $\mathrm{pO}_{2}$ in the $\mathrm{Ox}-\mathrm{HMP}$ group occurred after $30 \mathrm{~min}$ of $\mathrm{O}_{2}$ upload $(476.3 \pm 102.6 \mathrm{~mm}$ $\mathrm{Hg}$ ), which was only maintained for $15 \mathrm{~min}$ after the preload ended (479.2 $\pm 86.4 \mathrm{~mm} \mathrm{Hg}$ ). This differed from the rest of the pre-clinical studies, where $\mathrm{pO}_{2}$ levels reached were significantly higher, usually above $500 \mathrm{~mm} \mathrm{Hg}$, and more commonly between 700 and $800 \mathrm{~mm} \mathrm{Hg}$ [15, 20, 37]. We do not have a satisfactory explanation, although our experimental setting did show some important differences compared to other models. First, we obtained very inconsistent results regarding $\mathrm{pO}_{2}$ using an external membrane oxygenator in the first few trials; this was later replaced by a surface bubble oxygenator that supplied oxygenated perfusate directly. Second, perfusion oxygenation was only maintained for a short period (30 $\mathrm{min}$ ) at the beginning of the HMP (preload). Differences in $\mathrm{pO}_{2}$ levels might explain the inconclusive results. Darius et al. demonstrated in a pig kidney autotransplant model that continuous oxygen administration was able to reach high supraphysiological oxygen levels $\left(\mathrm{pO}_{2}\right.$ of $\left.700-800 \mathrm{~mm} \mathrm{Hg}\right)$ using the gas mixture Carbogen $\left(90 \% \mathrm{O}_{2}\right)$, and this strategy of oxygen supplementation during HMP might be the best preservation strategy to protect mitochondria compared to low levels of oxygen $\left(\mathrm{pO}_{2}\right.$ of $\left.220-240 \mathrm{~mm} \mathrm{Hg}\right)$; although results were similar in early kidney function [21]. Low and high levels of oxygen resulted in superior functional outcomes compared to HMP without active oxygenation. Additionally, using the same autotransplant model in a different study, we observed that only $2 \mathrm{~h}$ of oxygenation at the start of the HMP was sufficient to achieve the same mitochondrial protection and positive effects on early graft function compared to continuous oxygenation during HMP [22]. In both studies described above, a membrane oxygenator was used to oxygenate the perfusion fluid, and the same was true for the remaining pre-clinical trials that performed oxygenated $\operatorname{HMP}[15,20-22,38,41]$.

During standard HMP, the oxygen in the perfusion fluid was rapidly depleted, resulting in a relatively hypoxic perfusion environment at the end of the perfusion period; thus, hampering the oxygen-dependent processes.

Depletion of oxygen can collapse the electron transport chain in mitochondria, which is important for oxidative phosphorylation, aerobic respiration, and the generation of cellular ATP. ROS production is the consequence of the interaction of a dysfunctional respiratory chain with oxygen during reperfusion. Chouchani et al. [17] demonstrated that the accumulation of mitochondrial succinate originated from the citric acid cycle during ischemia, is primarily responsible for ROS production during ischemia-reperfusion. Under ischemia, a reverse electron transfer is established at Complex II. Succinate accumulates, and electron flux through the rest of 
the respiratory chain and ATP production is diminished. The reverse flux of electrons at Complex I results in the reduction of flavin $\left(\mathrm{FMNH}_{2}\right)$. The FMN deficient Complex I is unable to perform NADH oxidation to NAD that re-enters aerobic glycolysis and is unable to contribute to energy production. Aerobic glycolysis then stops and switches to the alternative fermentation pathway, causing lactate production. The release of $\mathrm{FMNH}_{2}$ into the mitochondrial matrix would have had a strong prooxidative effect. In the aqueous solution, fully reduced flavin rapidly reacts with oxygen, generating superoxide and hydrogen peroxide. The rapid non-enzymatic autooxidation of the reduced flavin with ROS production after reintroduction of oxygen might contribute to the transient burst of ROS during the initial phases of reperfusion. Dutkowski et al. [42] described that the end-ischemic oxygenated hypothermic liver perfusion advances electron transport in the mitochondrial respiratory chain during HMP. This decreases succinate and increases ATP at the end of HMP, subsequently improving graft function [42].

The detection of ATP by ${ }^{31} \mathrm{P}$ magnetic resonance spectroscopy during oxygenated HMP in an experimental pig model demonstrated increased ATP re-synthesis during Ox-HMP after an initial period of WIT or SCS, but not if both were combined. Therefore, after a period of WIT that defines DCD, HMP should be introduced immediately [12, 39, 43]. In our experimental setting, after a preestablished 30-min WIT, a positive effect of HMP was observed as a minor increase in the ATP production that appeared to be slightly better in the nOx-HMP group than the Ox-HMP group. However, a high level of proton leakage and the corresponding low level of spare respiratory capacity represented a loss of respiratory chain efficiency after WIT that was attenuated by nOxHMP and worsened by oxygen addition during Ox-HMP. Kaminski et al. determined oxygen consumption and ATP synthesis during non-oxygenated HMP in a pre-clinical porcine model after a WIT of 60 min [18]. The one-hour WIT reduced ATP level by $90 \%$. In nOx-HMP, the perfusate solution is recirculated without possible or significant re-equilibration with atmospheric oxygen, since ambient air inside the kidney container is enclosed by two lids, inner and outer. The $\mathrm{pO}_{2}$ of the preservation solution decreased rapidly from the atmospheric level and then stabilized. In our experimental setting, the mean $\mathrm{pO}_{2}$ in the $\mathrm{nOx}-\mathrm{HMP}$ group varied from $162.9( \pm 33.5) \mathrm{mm} \mathrm{Hg}$ at the basal point to $92.9( \pm 18.5) \mathrm{mm} \mathrm{Hg}$ at the end of the perfusion. In contrast, the authors showed that under nOx-HMP, the oxygen level in the perfusion solution remained at the atmospheric level (145 $\mathrm{mmHg}$ ) during a short period of time $(10 \mathrm{~min})$ and then rapidly and significantly decreased more profoundly than in our experience, reaching a final value of $6.8 \mathrm{mmHg}$. These findings may be related to a more severe ischaemic injury in their model.

In this study, the perfusate concentration of a major central metabolite, like lactate, was significantly higher in the Ox-HMP group than the nOx-HMP group and did not correspond to the expected decline under better oxygenation conditions, where the efficiency of cellular metabolism should have improved, and the overall anaerobic metabolic activity should have diminished. Recently, Darius et al. [21] showed that the relationship between oxygen concentration and regulation of oxygen-dependent Krebs cycle was dose-dependent, with the maximal amount of Krebs cycle activity and a corresponding increase in cellular ATP levels occurring with a high flow of oxygen. Lactate concentration in the low flow oxygen group and standard HMP group was similar and lactate perfusate concentration diminished only in the high flow oxygen group following upregulation of the Krebs cycle activity and the corresponding reduction of anaerobic metabolic activity [21]. Low $\mathrm{pO}_{2}$ levels in our study explained the low activation of aerobic metabolism and persistent dysfunction of the respiratory chain. Tracer studies using isotopically labeled metabolic 
substrates can be used to elucidate whether a detected metabolite has been produced de novo [39, $43,44,45]$. Using a combination of NMR and mass spectrometry, and an ex vivo donation after cardiocirculatory death porcine model of HMP, Patel et al. demonstrated that perfusate supplementation with a high concentration of oxygen (95\%) resulted in a greater degree of aerobic metabolism at the end of machine perfusion versus active aeration (21\%) [19].

Cell membrane damage may be inferred from the increased LDH level detected in the perfusate. Higher levels of LDH may coincide with increased leakage of cellular metabolites into the perfusate. Darius et al. [21] observed higher levels of perfusate LDH in the standard HMP and $\mathrm{HMPO}_{2}$ low groups when compared with the $\mathrm{HMPO}_{2}$ high groups. In this study, we were unable to demonstrate a significant difference between the Ox-HMP and nOx-HMP groups, probably due to a short oxygen supply.

To support our results of mitochondrial respiration, we determined antioxidant gene expression in tissue cultures. In a metabolic context of potentially less oxidative stress during nOx-HMP, SOD1 and catalase enzymes decreased significantly from the elevated levels reached after WIT. In contrast, during Ox-HMP, oxidative stress and the demand for SOD1 and catalase enzymes increased. Sustained oxidative stress could increase renal fibrosis by promoting EMT in proximal epithelial cells, among others. Indeed, we observed a decrease in E-cadherin and an increase in fibronectin, vimentin, and collagen under Ox-HMP conditions, although the changes were statistically not significant. This finding indicates that oxygen addition could lead to fibrosis; thus, compromising the outcomes of long-term grafts.

Finally, increased lipid peroxidation, demonstrated by the higher and significant MDA levels in graft tissue samples after Ox-HMP, supported the hypothesis that ROS levels increase at higher levels of oxygen. The level of lipid peroxidation determined in post-perfusion biopsy samples could be an indicator of tissue stress and kidney allograft post-KT evolution.

Several studies have identified some possible markers of ischemic injury in preservation solution during HMP, including perfusion parameters, although their utility in predicting outcomes is limited $[28,29]$. The data presented in this study match the findings of other studies that showed a constant decrease in $\mathrm{RI}$ and an increase in flow in Ox-HMP and nOx-HMP groups although without significant differences $[15,20,37,41]$. As reported previously, perfusion parameters were not correlated with renal function [28].

We previously identified a series of miRNAs, consisting of miR-210, miR-126, miR-127, miR-146, miR-10a, miR-101 miR-93, miR-27a, miR-26b, and miR-29a, as AKI biomarkers in clinical applications $[24,25]$. A subset of these miRNAs, comprising miR-101 and miR-126, showed the most significantly modified expression in response to preservation conditions. Functional analysis revealed that miR101 was associated with kidney development, cell adhesion, and endocytosis. Similarly, miR-126 was associated with kidney development, as well as microtubule-based transport and cell-cell adherens junctions, both of which are important characteristics and functions of proximal epithelial cells. The integrity of the renal peritubular capillary network is an important limiting factor in the recovery from renal IRI. miR-126 has been shown to improve vascular regeneration by mobilizing hematopoietic stem/progenitor cells. These miRNAs appear to participate in renal tissue recovery and could therefore represent useful biomarkers for allograft evaluation during preservation [23, 26].

We recognize that there are some limitations of this porcine auto-KT model. First, the sample size of the experimental Ox-HMP group was small, hindering the identification of statistical 
differences. Second, porcine models using young and healthy pigs without preexisting kidney diseases may require a longer duration of ischemic injury for visible differences in pre and postpreservation histology. Post-KT animal recovery and survival may have limitations in the development of delayed graft function, secondary to different causes of variable severity.

Finally, the hypothesis that oxygen upload by integrated bubble oxygenation during LifePort $^{\circledR}$ $\mathrm{HMP}$ can uniformly increase $\mathrm{pO}_{2}$ levels above $500 \mathrm{~mm} \mathrm{Hg}$ has not yet been proven. Our experiments did not demonstrate the capability of the $\mathrm{O}_{2}$ early preload strategy in maintaining supraphysiological $\mathrm{pO}_{2}$ beyond a short while after completing active oxygenation, in contrast to the more common use of membrane oxygenation.

\section{Conclusions}

Brief bubble Ox-HMP did not demonstrate a positive effect on renal function. On the other hand, Ox-HMP appeared to be associated with an increase in lipid peroxidation and a greater expression of oxygenation enzyme genes. Respiratory chain dysfunction persisted despite oxygen supplementation, and an upward trend in the expression of EMT genes was observed.

Therefore, the role, safety, and method of oxygen addition still need to be elucidated. Currently, this Ox-HMP method cannot be considered standard practice.

The aerobic mechanism under high perfusate $\mathrm{pO}_{2}$ levels, that were not reached by a short initial oxygen supplementation model, seems to be better supported in the literature. Low $\mathrm{pO}_{2}$ levels in our study could explain a deficient activation of aerobic metabolism and persistent dysfunction of the respiratory chain.

\section{Abbreviations}

$\begin{array}{ll}\text { AKI } & \text { Acute kidney injury } \\ \text { ATN } & \text { Acute tubular necrosis } \\ \text { AUC } & \text { Area under curve } \\ \triangle C t \text { (DeltaCt) } & \text { Difference in Crossing threshold } \\ \text { DCD } & \text { Donation after circulatory death } \\ \text { DCT } & \text { Differential crossing threshold } \\ \text { DGF } & \text { Delayed graft function } \\ \text { ECD } & \text { Expanded criteria donor } \\ \text { EMT } & \text { Epithelial mesenchymal transition } \\ \text { FBS } & \text { Fetal Bovine Serum } \\ \text { HMP } & \text { Hypothermic machine perfusion } \\ \text { IN } & \text { Ischemic necrosis } \\ \text { IRI } & \text { Ischemia reperfusion injury } \\ \text { ITS } & \text { Insulin-Transferrin-Selenium } \\ \text { MDA } & \text { Malondialdehyde } \\ \text { miRNA } & \text { microRNA } \\ \text { mRNA } & \text { Messenger RNA } \\ \text { nOx-HMP } & \text { O2 non supplemented O2 HMP } \\ \text { OCR } & \text { Oxygen consumption rate } \\ \text { Ox-HMP } & \text { O2 supplemented HMP }\end{array}$




$\begin{array}{ll}\text { PNF } & \text { Primary non function } \\ \text { PSG } & \text { Penicillin, Streptomycin } \\ \text { RI } & \text { Resistive index } \\ \text { ROS } & \text { Reactive oxygen species } \\ \text { RT-PCR } & \text { Real time polymerase chain reaction } \\ \text { SCS } & \text { Static cold storage } \\ \text { SOD } & \text { Superoxide dismutase } \\ \text { WIT } & \text { Warm ischemic time }\end{array}$

\section{Acknowledgments}

The authors thank Organ Recovery Systems (Itasca, IL, USA) for providing the LifePort ${ }^{\circledR}$ kidney transporter device and disposables and particularly, Peter DeMuylder for technical assistance.

\section{Additional Materials}

The following additional materials are uploaded at the page of this paper.

1. Figure S1: Experimental study flowchart

2. Figure S2: (A) LifePort ${ }^{\circledR}$ modified perfusion circuit. Oxygenation is set up $500 \mathrm{ml} / \mathrm{min} 100 \% 02$. (B) Membrane oxygenator built into the sterile disposable tubing set in the LifePort ${ }^{\circledR}$ kidney transporter. (C) Oxygenated perfusate enters the perfusion circuit at the return line of the perfusion circuit. (D) Wash line enters the hollow-fibre membrane oxygenator in order to continuously oxygenate perfusate.

3. Figure S3: pO2 evolution along HMP. 3a pO2 continuously decrease along HMP in the nOxHMP group. 3b Membrane oxygenator supplied $\mathrm{O} 2$ in a highly inconsistent manner. 3c pO2 initially increase during the first $30 \mathrm{~min} \mathrm{O} 2$ upload and then decrease until the end of perfusion.

4. Figure S4: Perfusion parameters for Ox-HMP and nOx-HMP porcine kidneys. (a) Flow and (b) Resistance.

5. Figure S5: EMT markers expression, estimated by qRT-PCR. E-cadherin as an epithelial integrity and absence of EMT marker increases during nOx-HMP (gray bars) and after the warm ischemia period (white bars). On the contrary, vimentin, fibronectin and collagen as EMT markers, decrease during nOx-HMP. Conversely, Ox-HMP (black bars) induces a decrease of e-cadherin expression and higher levels of fibronectin, vimentin and collagen from those after warm ischemia.

\section{Author Contributions}

Study design: Victoria Gómez-Dos-Santos, Francisco Javier Burgos-Revilla, María Laura GarcíaBermejo, Alberto Alcázar-González; Data collection: Victoria Gómez-Dos-Santos, Vital HeviaPalacios; Analysis and interpretation of data: Victoria Gómez-Dos Santos, Francisco Javier BurgosRevilla, María Laura García-Bermejo, Alberto Alcázar-González; Laura Salinas-Muñoz, Vital Hevia Palacios; Drafting of the manuscript: Victoria Gómez-Dos-Santos, Vital Hevia-Palacios; Critical Revisión of the Manuscript: Francisco Javier Burgos-Revilla, María Laura García-Bermejo, Alberto Alcázar-González; Obtaining funding: Victoria Gómez-Dos Santos; Technical or material support: M 
Edurne Ramos-Muñoz, Laura Salinas-Muñoz, Elisa Conde-Moreno, Alejandro Escobar-Peso, Ana Belén Serrano-Moreno, Ana Saiz González, Miriam Menacho-Román.

\section{Funding}

The design and conduct of this study (PI14/01441) were supported by grants from the Instituto de Salud Carlos III (Plan Estatal de I+D+i 2013-2016), the Mutua Madrileña Foundation and the Intramural Call for Aid to Research Projects of new researchers, associated clinical researchers and / or emerging groups of the Ramón y Cajal University Hospital (IMP-16 IRYCIS). All the miRNAs are covered by intellectual property laws: P200901825, P201130546, P201130545, P201132023, P201231999; PCT ES2010070579, PCT ES2012070858. MLGB is inventor. Patents are temporally licensed to investors for validation studies.

\section{Competing Interests}

The authors have declared no conflicts of interest.

\section{References}

1. Laupacis A, Keown P, Pus N, Krueger H, Ferguson B, Wong C, et al. A study of the quality of life and cost utility of renal transplantation. Kidney Int. 1996; 50: 235-242.

2. Messina M, Diena D, Dellepiane S, Guzzo G, Lo Sardo L, Fop F, et al. Long-term outcomes and discard rate of kidneys by decade of extended criteria donor age. Clin J Am Soc Nephrol. 2017; 12: 323-331.

3. Port FK, Bragg-Gresham JL, Metzger RA, Dykstra DM, Gillespie BW, Young EW, et al. Donor characteristics associated with reduced graft survival: An approach to expanding the pool of kidney donors. Transplantation. 2002; 74: 1281-1286.

4. Johnston TD, Thacker LR, Jeon H, Lucas BA, Ranjan D. Sensitivity of expanded-criteria donor kidneys to cold ischaemia time. Clin Transplant. 2004; 18: 28-32.

5. Moers C, Smits JM, Maathuis M-H, Treckmann J, van Gelder F, Napieralski BP, et al. Machine perfusion or cold storage in deceased-donor kidney transplantation. New Engl J Med. 2009; 360: 7-19.

6. Treckmann J, Moers $C$, Smits JM, Gallinatet $A$, Maathuis $M H$, van Kasterop-Kutz $M$, et al. Machine perfusion versus cold storage for preservation of kidneys from expanded criteria donors after brain death. Transpl Int. 2011; 24: 548-554.

7. Jochmans I, Moers C, Smits JM, Leuvenink HG, Treckmann J, Paul A, et al. Machine perfusion versus cold storage for the preservation of kidneys donated after cardiac death: A multicenter, randomized, controlled trial. Ann Surg. 2010; 252: 756-764.

8. Watson CJ, Wells AC, Roberts RJ, Akoh JA, Friend PJ, Akyol M, et al. Cold machine perfusion versus static cold storage of kidneys donated after cardiac death: A UK multicenter randomized controlled trial. Am J Transplant. 2010; 10: 1991-1999.

9. Wilson DF, Erecińska M, Drown C, Silver IA. The oxygen dependence of cellular energy metabolism. Arch Biochem Biophys. 1979; 195: 485-493.

10. Dittrich S, Groneberg DA, von Loeper J, Lippek F, Hegemann O, Grosse-Siestrup C, et al. Influence of cold storage on renal ischemia reperfusion injury after non-heart-beating donor 
explantation. Nephron Exp Nephrol. 2004; 96: e97-e102.

11. Hosgood S, Nicholson M. Oxygen supplementation supports energy production during hypothermic machine perfusion in a model of donation after circulatory death donors. Transplantation. 2019; 103: 1980-1981.

12. Lazeyras FB, Hergt M, Vallee J, Nastasi A, Ruttimann R, Morel P, et al. ATP resynthesis of pig kidneys during oxygenated hypothermic perfusion assessed by 31P CSI. Magn Reson Mater Phy. 2008; 21: 272-273.

13. O'Callaghan J, Pall K, Pengel L. Supplemental oxygen during hypothermic kidney preservation: A systematic review. Transplant Rev. 2017; 31: 172-179.

14. Hosgood SA, Nicholson HF, Nicholson ML. Oxygenated kidney preservation techniques. Transplantation. 2012; 93: 455-459.

15. Hoyer DP, Gallinat A, Swoboda S, Wohlschlaeger J, Rauen U, Paul A, et al. Influence of oxygen concentration during hypothermic machine perfusion on porcine kidneys from donation after circulatory death. Transplantation. 2014; 98: 944-950.

16. Coppolino G, Leonardi G, Andreucci M, Bolignano D. Oxidative stress and kidney function: A brief update. Curr Pharm Des. 2019; 24: 4794-4799.

17. Chouchani ET, Pell VR, Gaude E, Aksentijević D, Sundier SY, Robb EL, et al. Ischaemic accumulation of succinate controls reperfusion injury through mitochondrial ROS. Nature. 2014; 515: 431-435.

18. Kaminski J, Delpech PO, Kaaki-Hosni S, Promeyrat X, Hauet T, Hannaert P. Oxygen consumption by warm ischemia-Injured porcine kidneys in hypothermic static and machine preservation. J Surgical Res. 2019; 242: 78-86.

19. Patel K, Smith TB, Neil DA, Thakker A, Tsuchiya Y, Higgs EB, et al. The effects of oxygenation on ex vivo kidneys undergoing hypothermic machine perfusion. Transplantation. 2019; 103: 314322.

20. Gallinat A, Paul A, Efferz P, Lüer B, Swoboda S, Hoyer D, et al. Role of oxygenation in hypothermic machine perfusion of kidneys from heart beating donors. Transplantation. 2012; 94: 809-813.

21. Darius $T$, Vergauwen $M$, Smith TB, Patel $K$, Craps J, Joris $V$, et al. Influence of different partial pressures of oxygen during continuous hypothermic machine perfusion in a pig kidney ischemia-reperfusion autotransplant model. Transplantation. 2020; 104: 731-743.

22. Darius $T$, Vergauwen $M$, Smith TB, Gerin I, Joris $V$, Mueller $M$, et al. Brief $\mathrm{O}_{2}$ uploading during continuous hypothermic machine perfusion is simple yet effective oxygenation method to improve initial kidney function in a porcine autotransplant model. Am J Transplant. 2020; 20: 2030-2043.

23. Lorenzen JM. Vascular and circulating microRNAs in renal ischaemia-reperfusion injury. J Physiol. 2015; 593: 1777-1784.

24. Aguado-Fraile E, Ramos E, Conde E, Rodríguez M, Liaño F, García-Bermejo ML. MicroRNAs in the kidney: Novel biomarkers of acute kidney injury. Nefrologia. 2013; 33: 826-834.

25. Aguado-Fraile E, Ramos E, Conde E, Rodríguez M, Martín-Gómez L, Lietor A, et al. A pilot study identifying a set of microRNAs as precise diagnostic biomarkers of acute kidney injury. Plos One. 2015; 10: e0127175.

26. Godwin JG, Ge X, Stephan K, Jurisch A, Tullius SG, lacomini J. Identification of a microRNA signature of renal ischemia reperfusion injury. Proc Natl Acad Sci. 2010; 107: 14339-14344. 
27. Khalid U, Ablorsu E, Szabo L, Jenkins RH, Bowen T, Chavez R, et al. MicroRNA-21 (miR-21) expression in hypothermic machine perfusate may be predictive of early outcomes in kidney transplantation. Clin Transplant. 2016; 30: 99-104.

28. Jochmans I, Moers C, Smits JM, Leuvenink HG, Treckmann J, Paul A, et al. The prognostic value of renal resistance during hypothermic machine perfusion of deceased donor kidneys. Am J Transplant. 2011; 11: 2214-2220.

29. Gómez V, Orosa A, Rivera M, Diez-Nicolás V, Hevia V, Alvarez S, et al. Resistance index determination in the pre and post kidney transplantation time points in graft dysfunction diagnosis. Transplant Proc. 2015; 47: 34-37.

30. Bhangoo RS, Hall IE, Reese PP, Parikh CR. Deceased-donor kidney perfusate and urine biomarkers for kidney allograft outcomes: A systematic review. Nephrol Dial Transpl. 2012; 27: 3305-3314.

31. Moers C, Varnav OC, van Heurn E, Jochmans I, Kirste GR, Rahmel A, et al. The value of machine perfusion perfusate biomarkers for predicting kidney transplant outcome. Transplantation. 2010; 90: 966-973.

32. Hoogland ER, de Vries EE, Christiaans MH, Winkens B, Snoeijs MG, van Heurn LW. The value of machine perfusion biomarker concentration in DCD kidney transplantations. Transplantation. 2013; 95: 603-610.

33. Betteridge DJ. What is oxidative stress?. Metabolism 2000; 49: 3-8.

34. Eltzschig HK, Eckle T. Ischemia and reperfusion - from mechanism to translation. Nat Med. 2011; 17: 1391-1401.

35. Dey S, Sidor A, O'Rourke B. Compartment-specific control of reactive oxygen species scavenging by antioxidant pathway enzymes. J Biol Chem. 2016; 291: 11185-11197.

36. Birben E, Sahiner UM, Sackesen C, Erzurum S, Kalayci O. Oxidative stress and antioxidant defense. World Allergy Organ J. 2012; 5: 9-19.

37. Darius T, Gianello P, Vergauwen M, Mourad N, Buemi A, De Meyer M, et al. The effect on early renal function of various dynamic preservation strategies in a preclinical pig ischemiareperfusion autotransplant model. Am J Transplant. 2019; 19; 752-762.

38. Thuillier R, Allain G, Celhay O, Hebrard W, Barrou B, Badet L, et al. Benefits of active oxygenation during hypothermic machine perfusion of kidneys in a preclinical model of deceased after cardiac death donors. J Surg Res. 2013; 184: 1174-1181.

39. Lazeyras F, Buhler L, Vallee JP, Hergt M, Nastasi A, Ruttimann R, et al. Detection of ATP by “in line" 31P magnetic resonance spectroscopy during oxygenated hypothermic pulsatile perfusion of pigs' kidneys. Magn Reson Mater Phy. 2012; 25: 391-399.

40. Chatauret N, Coudroy R, Delpech PO, Vandebrouck C, Hosni S, Scepi M, et al. Mechanistic analysis of nonoxygenated hypothermic machine perfusion's protection on warm ischemic kidney uncovers greater eNOS phosphorylation and vasodilation. Am J Transplant. 2014; 14: 2500-2514.

41. Venema LH, Brat A, Moers C, 't Hart NA, Ploeg RJ, Hannaert P, et al. Effects of oxygen during long-term hypothermic machine perfusion in a porcine model of kidney donation after circulatory death. Transplantation. 2019; 103: 2057-2064.

42. Dutkowski P, Guarrera JV, de Jonge J, Martins PN, Porte RJ, Clavien PA, et al. Evolving trends in machine perfusion for liver transplantation. Gastroenterology. 2019; 156: 1542-1547.

43. Buchs JB, Lazeyras F, Ruttimann R, Nastasi A, Morel P. Oxygenated hypothermic pulsatile 
perfusion versus cold static storage for kidneys from non heart-beating donors tested by in-line ATP resynthesis to establish a strategy of preservation. Perfusion. 2011; 26: 159-165.

44. Nath J, Smith T, Hollis A, Ebbs S, Canbilen SW, Tennant DA, et al. $13 \mathrm{C}$ glucose labelling studies using 2D NMR are a useful tool for determining ex vivo whole organ metabolism during hypothermic machine perfusion of kidneys. Transplant Res. 2016; 5: 7.

45. Nath J, Guy A, Smith TB, Cobboldet M, Inston NG, Hodson J, et al. Metabolomic perfusate analysis during kidney machine perfusion: The pig provides an appropriate model for human studies. Plos One. 2014; 9: e114818.

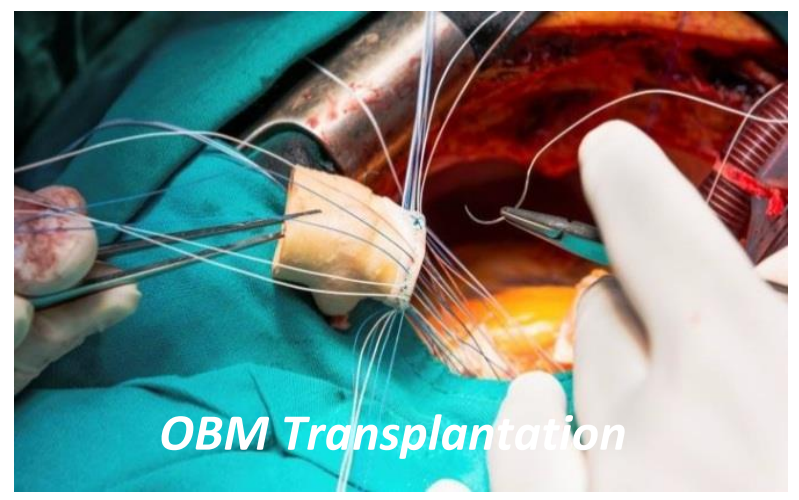

Enjoy OBM Transplantation by:

1. Submitting a manuscript

2. Joining in volunteer reviewer bank

3. Joining Editorial Board

4. Guest editing a special issue

For more details, please visit:

http://www.lidsen.com/journals/transplantation 